\title{
Transporte fluvial e turismo: uma análise das potencialidades dos cânions do rio São Francisco e do atracadouro da Terra Caída em Sergipe (Brasil)
}

\section{River transportation and tourism: an analysis of the potential of the São Francisco River canyons and Terra Caída dock in Sergipe (Brasil)}

\author{
Suzana de Mendonça Rodrigues (RODRIGUES, S. de M.) ${ }^{*}$ e \\ Fernanda Meneses de Miranda Castro (CASTRO, F. M. de M.) ${ }^{* * *}$
}

\begin{abstract}
RESUMO - Esse artigo teve como objetivo apresentar o cenário do Estado de Sergipe (Brasil) frente à utilização dos transportes fluviais, sobretudo para o turismo, tomando como objetos de estudo os cânions do Rio São Francisco e o atracadouro de Porto do Mato. Para tanto, este estudo buscou demonstrar um breve histórico da utilização das vias aquaviárias no Brasil com ênfase no uso dos transportes fluviais. Procurou-se fazer uma discussão sobre a intermodalidade, como meio facilitador para o deslocamento dos turistas, além de expor o potencial de atratividade que os modais podem ter frente aos usuários. Em relação aos atracadouros de Sergipe notou-se que existe uma discrepância entre os destinos que exploram as hidrovias, visto que enquanto os Cânions de Xingó recebem grande fluxo de visitantes e estão com uma infraestrutura turística mais adequada, Porto do Mato possui menor visibilidade turística e não tem infraestrutura. Em ambos os destinos os envolvidos com o trade turístico carecem de melhor capacitação.
\end{abstract}

Palavras-Chaves: Transporte fluvial; Turismo; Sustentabilidade.

ABSTRACT - This paper aimed to present a prospect of Sergipe State (Brazil) facing the use of the river transportation, especially for tourism, taking as objects of study the canyons of São Francisco River and the Porto Mato dock. Therefore, this study sought to demonstrate a short history about the Brazilian waterways emphasizing the use of the river transportation. It was discussed about the intermodality as a mean to make easier the tourists movement, and besides to show the attractiveness potential that these modes can have with the users. In relation to the docks in Sergipe, it was noted that there is a discrepancy among the destinations that explore the waterways, since the Xingó Canyons receive a large flow of visitors and have a more appropriate tourism infrastructure, Porto do Mato has less visibility and has no infrastructure. In both destinations, the people involved with the trade need a better qualification.

Key words: River transportation; Tourism; Sustainability.

\footnotetext{
* Acadêmica do Curso de Turismo da Universidade Federal de Sergipe (UFS). Bolsista do Programa de Incentivo à Iniciação Científica - PIIC da Universidade Federal de Sergipe (UFS). Endereço: Avenida Adélia Franco, 3662. Condomínio Moradas do Adriático, bloco Ravenna, ap. 804, Luzia. CEP 49048-010 - Aracaju - Sergipe (Brasil). Telefone: (79) 9135 4308. E-mail: smr.tur@ hotmail.com

** Graduação em Turismo pela Faculdade de Turismo da Bahia. Graduação em Administração pela Universidade Católica do Salvador. Especialização em Educação pela Faculdade Visconde de Cairu. Mestrado em Cultura e Turismo pela Universidade Estadual de Santa Cruz. Professora do Núcleo de Turismo da Universidade Federal de Sergipe (UFS). Endereço: Rua Alberto Fiúza, 571. Condomínio Moradas do Bosque, edifício Pinho Silvestre, ap. 702, Imbuí. CEP 41720-120 - Salvador - Bahia (Brasil). Telefones: (71) 3230-1855/8108-0043 e (79) 9145-3252. E-mail: ferdicastro@ hotmail.com
} 


\section{INTRODUÇÃO}

A ligação entre transportes e turismo é notável, pois para que haja turismo é imprescindível a utilização dos meios de transportes. No entanto, os modais são escolhidos de acordo com a necessidade de deslocamento e maior comodidade do viajante. Muitas vezes é preciso utilizar mais de um modal para chegar a determinado destino, o que é facilitado através da integração entre os modais.

Os transportes também podem aparecer como uma atração, onde o deslocamento e a atração turística se confundem sobretudo se tratando de transporte aquaviário, em especial o fluvial - objeto de estudo dessa pesquisa - pois embora o Brasil possua grandes rios, as hidrovias são pouco utilizadas como meio de transporte convencional, devido a pouca densidade destes.

Os objetos centrais deste estudo são o povoado de Porto do Mato e os cânions do rio São Francisco. O povoado de Porto do Mato pertence ao município de Estância e localiza-se ao centro sul do Estado de Sergipe, abriga o atracadouro e desatracadouro da Terra Caída, utilizado, sobretudo por turistas que desejam visitar as ilhas fluviais próximas ao povoado. Os cânions do rio São Francisco, também conhecidos como cânions do Xingó, pertencem a Canindé de São Francisco, a cidade do sertão sergipano que abriga a Companhia Hidrelétrica do São Francisco e recebe um fluxo de turistas considerável durante os meses do ano.

Desse modo, o objetivo central deste trabalho foi analisar o uso turístico do transporte fluvial nos portos de Terra Caída e nos Cânions de São Francisco, ambos no estado de Sergipe.

Para tanto foi realizada pesquisa bibliográfica com o intuito de apresentar a utilização das hidrovias e dos transportes fluviais, desde o período colonial até a atualidade, por meio de um resgate sócio-histórico preliminar. Além disso, buscou-se elucidar a ligação existente entre transportes e turismo, enfatizando a simultaneidade do uso do transporte e do turismo, ou seja, quando os transportes podem aparecer como uma atração.

O presente trabalho foi construído através de pesquisas bibliográficas e visitas em campo em uma das principais agências de turismo receptivo que oferece o destino Cânions do rio São Francisco, ou Cânions do Xingó, como são mais conhecidos e ao povoado de Porto do Mato, lugar onde foi realizada pesquisa de caráter qualitativo. 
A pesquisa confirmou a pouca utilização das hidrovias do estado de Sergipe, assim como as brasileiras. A pesquisa sugeriu que se amplie a utilização dos transportes fluviais do Estado de Sergipe como meio facilitador de deslocamentos, pois, percebeuse que estes podem ser utilizados compondo o produto turístico e se mostrando como diferencial nas regiões que os utilizam.

\section{UM BREVE HISTÓRICO DAS HIDROVIAS NO BRASIL}

As hidrovias são utilizadas no Brasil antes mesmo do período de colonização e permanecem em uso até os dias de hoje. Embora apareçam de forma bastante tímida no cenário do país o usufruto desses modais são notados, sobretudo nas regiões que possuem pouco acesso rodoviário que proporcionariam o uso do transporte mais utilizado no Brasil.

A utilização dos rios marcou a história, pois através deles os portugueses puderam percorrer o país. Os portugueses buscavam captar o máximo de recursos possível extraindo assim da colônia o que achavam de interesse e produzir os bens para serem comercializados na metrópole. Houve a preocupação em abrir caminhos para que pudessem captar o que interessava à metrópole, porém não se preocuparam em desenvolver o país por quaisquer que fossem as vias de comunicação (MARQUES, 2000).

Ainda de acordo com Marques (2000), o povoamento do Brasil ocorreu através de rios brasileiros merecendo destaque o rio Tietê, o Amazonas, o Tapajós, o Madeira, o Pardo e o Taquari. Pelas vias fluviais transportavam cargas proporcionando menos riscos aos viajantes que por caminhos terrestres.

$\mathrm{O}$ autor ainda coloca que no período colonial o comércio era realizado por meio de navios, sendo assim a utilização dos portos propiciou a criação de cidades, pois de acordo com o valor representativo das capitanias estas se transformavam em centros de importação e exportação (MARQUES, 2000).

O sistema de transporte terrestre sofria dificuldades de ser inserido, pois tanto os aspectos naturais como os políticos "direcionavam" os meios de transportes para as vias hidroviárias. 
Em 1808 no governo de D. João VI os portos foram abertos para o comércio advindo de países que não fossem contra o governo de Portugal (GOMES, 2007). E a Inglaterra era a nação que exercia grande poder em relação ao comércio existente nos portos brasileiros. Naquela época, o rei instituiu que houvesse melhorias relacionadas à navegação nos rios. Também mandou que abrissem estradas para que houvesse maior comunicação entre as capitanias e a corte. Porém, o período colonial foi marcado pela precariedade dos meios de comunicação, mesmo com a ampliação, as vias de acesso se mostraram insuficientes.

De acordo com Marques (2000) em 29 de agosto de 1928 foi criada uma lei que dispôs sobre o dever do governo imperial, provincial e municipal ampliar os meios de transportes e conseqüentemente os meios de comunicação. A lei abrangeu a navegação dos rios, construção de estradas e pontes e etc.

No período regencial as províncias prosseguiam com a busca em ampliar os meios de comunicação, inclusive por meio das vias fluviais. Porém, de acordo com Bastos (1971) apud Marques (2000, p. 101) “o período regencial esgotou-se sem que houvesse sido realizada qualquer obra de vulto no setor de transportes."

A partir de 1850 no período do $2^{\circ}$ reinado ampliou-se a navegação de longo percurso (MARQUES, 2000). A navegação a vapor mostrou-se crescente a qual ocupava as costas brasileiras percorrendo o litoral.

As vias de transportes não tiveram continuidade nos planejamentos dos governos, visto que ao implantar um sistema de transporte deixam de ampliar os outros já existentes (GOULARTI FILHO, 2010). Dessa forma, nota-se a falta de continuidade dos processos já implantados e o direcionamento de políticas públicas aos novos sistemas de transportes sem buscar integrá-los.

Segundo Freyre (2004) no território que atualmente denomina-se Nordeste os rios tiveram grande importância na ascensão política e econômica da região, visto que proporcionavam o cultivo da cana-de açúcar no período açucareiro principal produto da economia brasileira. As embarcações fluviais serviam tanto para a pesca, como para o uso pessoal, era algo imbricado na cultura no Nordeste do país. "Muitas vezes temos visto as jangadas chegarem às praias cheias de peixes de cor, ainda vivos e pulando [...]" (FREYRE, 2004, p. 69). O mesmo autor também destacou que a utilização dos

\footnotetext{
${ }^{1}$ BASTOS, H. O ABC dos transportes. Rio de Janeiro: Ministério dos Transportes, 1971.
} 
transportes fluviais na memória da população do Norte remetia a cultura europeia, ou seja, era visto como algo valorizado também pela classe dominante.

De tal modo se desenvolveu o complexo do rio entre a gente mais ilustre do Nordeste, que se tornou chic tirar o retrato, nas fotografias francesas, dentro de botes ou de canoas, as sinhazinhas empurrando remos, os meninos fingindo remar (FREYRE, 2004, p. 64).

$\mathrm{Na}$ atualidade os transportes aquaviários são utilizados, sobretudo para o transporte de cargas. $\mathrm{O}$ custo deste tipo de transporte apresenta-se mais baixo que o ferroviário, rodoviário e aeroviário, porém o valor da implantação das vias aquaviárias está ligado às condições geográficas e topográficas da região. O preço mostra-se mais em conta também em relação às instalações das vias hidroviárias e aos fretes dos transportes de cargas. A construção de um quilômetro de ferrovia custa 1,4 milhões de reais, a construção da mesma quilometragem de rodovia asfaltada custa $R \$ 300.000$ enquanto de hidrovia custa apenas $\mathrm{R} \$ 30.000(\text { OLIVA, 2002) })^{2}$. O uso dos mais variados modais é importante para o transporte quer seja de pessoas ou de cargas. De acordo com Mello (1984) apud Marques (2000, p.104) “'cada modo de transporte tem seu lugar num sistema complexo de movimentação, dificilmente alguma modalidade pode ser excluída, quando se quer dotar uma região de um sistema adequado de escoamento de sua produção".

Oliva (2002) também coloca que o uso dos transportes fluviais pode ser vantajoso em relação ao preço comparado com outros transportes. Porém, em contrapartida por ser realizado em vias naturais podem alterar a paisagem natural e provocar mudanças nos processos da natureza. Além disso, se houver acidentes a carga pode ser estragada.

Segundo Oliva (2008), o Brasil possui cerca de 13 mil Km de vias navegáveis utilizadas economicamente para o transporte de cargas e passageiros, podendo atingir cerca de 44 mil $\mathrm{Km}$ navegáveis, caso sejam realizadas obras de infraestrutura em outros 29 mil Km de vias naturalmente disponíveis. Porém, para ampliar as vias navegáveis é

\footnotetext{
${ }^{2}$ OLIVA, T. J. Guie a turma pela Amazônia. São Paulo: abril de 2002. Ano XVII, n. 151. Revista Nova Escola. Disponível em: <http://revistaescola.abril.com.br/ensino-medio/guie-turma-pela-amazonia425636.shtml>. Acesso em: 14/09/2010.

${ }^{3}$ MELLO, J. C. Transportes e Desenvolvimento Econômico. Brasília: EBTU, 1984.
} 
necessário que se realize planejamentos adequados a fim de utilizar os recursos de forma sustentável.

De acordo com o Ministério da Integração Nacional (2010a), a Amazônia possui o maior percentual de vias hidroviárias do Brasil. A Bacia Amazônica comporta alguns dos mais extensos rios. São eles: Amazonas, Solimões, Madeira, Negro, Japurá, Tapajós, Purus, Xingu, Içá, Juruá. Além desses o país possui outros rios de grande dimensão, entre os maiores estão: Rio Tocantins e Rio Araguaia (Bacia TocantinsAraguaia), Rio Paraná, Rio Uruguai, Rio Paraguai (Bacia da Prata), e Rio São Francisco (Bacia do São Francisco) ${ }^{4}$.

Desse modo, notou-se que as vias aquaviárias fazem parte do contexto de construção de memória dos brasileiros, pois muito antes da colonização do país os rios já eram explorados, por meio de embarcações, porém estas se modificaram com o tempo e ganharam novos usos. No entanto, estas vias são utilizadas aquém do seu potencial, visto que os governantes do Brasil privilegiam os transportes rodoviários e aeroviários.

\section{ANALISANDO A RELAÇÃO DOS TRANSPORTES COM O TURISMO}

A atividade turística é uma atividade complexa, visto que utiliza diversos serviços que representam o trade turístico. É de fundamental importância que todos os serviços sejam de boa qualidade para que o turista tenha experiências construtivas e retorne satisfeito para o destino de origem.

O transporte está intrinsecamente ligado ao turismo, levando-se em consideração que para existir turismo é necessário que haja deslocamento. Os diversos meios de transportes são essenciais aos deslocamentos. No entanto, a escolha do modal deve estar ligada as condições de cada território turístico, pois somente dessa forma é possível escolher o modal que mais se adequa as necessidades dos turistas.

O custo de transporte é composto de dois elementos bem distintos: o elemento monetário, representado pela tarifa que ele deve pagar para

\footnotetext{
${ }^{4}$ Bacias Hidrográficas e Rios. Disponível em: <http://www.portalbrasil.net/brasil_hidrografia.htm>. Acesso em: 15/09/2010.
} 
obter o serviço, e um elemento qualitativo, que inclui uma série de facilidades que ele espera receber com a prestação do serviço (DI RONÁ, 2002, p. 8).

Ainda segundo Di Roná (2002), os transportes podem sofrer crises ou até mesmo deixar de ser usados se não oferecerem vantagens aos clientes, desde que haja concorrência. De fato, pode-se observar que existem modais que competem entre si de acordo com os serviços que oferecem e a distância percorrida. Além disso, atualmente existe maior integração entre os modais embora seja ainda incipiente.

As empresas usam diversos recursos: modificam o produto, aumentam sua utilidade, descobrem novos usos, ampliam o mercado pela descoberta ou criação de novos consumidores, criam novas mercadorias ou convencem os consumidores de que seus produtos têm mais qualidade ou utilidade que os dos seus concorrentes (AUGUSTO, 1985, apud DI RONÁ, 2002, p. 8) 5 $^{5}$.

O transporte estudado no momento é o fluvial que se encaixa no grupo dos transportes aquaviários. "As vias em que os meios de transportes se deslocam sobre as águas - as aquavias -, que, por sua vez, se distinguem em vias marítimas, vias fluviais e vias lacustres" (DI RONÁ, 2002, p. 7). Embora o uso de transportes fluviais não seja constante em todas as regiões, assim como os outros modais as estratégias de utilização devem ser pensadas a fim de impulsionar a existência de demanda e movimentar os diversos modais, bem como se observa atualmente a reinvenção do uso de tais tipos de transportes para o turismo.

\section{A IMPORTÂNCIA DA BACIA DO SÃO FRANCISCO PARA OS BRASILEIROS}

A bacia do rio São Francisco mostra-se bastante importante para o Brasil visto que representa o maior rio legitimamente brasileiro ${ }^{6}$. Milhares de brasileiros vivem na região circunvizinha dessa bacia, visto que esta atinge sete Estados brasileiros, ou seja, é necessário que o planejamento observe os aspectos sócio-históricos.

\footnotetext{
${ }^{5}$ AUGUSTO, A. et al. Dicionário de Economia. São Paulo, Abril Cultural, 1985.

${ }^{6}$ Bacias Hidrográficas e Rios. Disponível em: <http://www.portalbrasil.net/brasilhidrografia.htm>. Acesso em: 15/09/2010.
} 
Segundo dados do Ministério da Integração Nacional (2010b), a bacia do rio São Francisco, nasce na serra do Canarana localizada no município de São Roque de Minas, no estado de Minas Gerais (MG). Possui 168 afluentes. Os índices pluviométricos sofrem alteração de acordo com a localização geográfica, em sua nascente a pluviometria é de em média 1900 milímetros (mm), sendo que no semiárido nordestino chega a $350 \mathrm{~mm}$.

Da nascente à cachoeira de Pirapora é denominado Alto do São Francisco, da cachoeira de Pirapora até a barragem de Xingó denomina-se de Submédio São Francisco, e de Xingó até o Oceano Atlântico é nomeado de Baixo do São Francisco.

O rio banha os Estados da Bahia, Sergipe, Minas Gerais, Pernambuco, Alagoas, porém abrange também o estado de Goiás e o Distrito Federal. O Cânion de Xingó localizado no baixo do rio São Francisco e em Sergipe desemboca no Oceano Atlântico no município de Brejo Grande.

A barragem que abrange Xingó, Paulo Afonso, Itaparica, Moxotó e Sobradinho, foi construída com a finalidade de gerar energia elétrica independente da época do ano, e fica aos cuidados da CHESF (Companhia de Hidrelétrica do São Francisco).

O Governo Federal expõe o Projeto de Integração do Rio São Francisco, que trata da transposição do referido rio, o qual está sendo desenvolvido atualmente no território brasileiro ${ }^{7}$. Tal projeto faz parte do Programa de Aceleração do Crescimento 2007-2010 e foi criado pelo Governo Federal, está sob a responsabilidade do Ministério da Integração Nacional. A iniciativa vem sendo consolidada juntamente com o Ministério do Meio Ambiente. A idéia é que a partir do projeto do São Francisco seja construído o maior túnel para transportar água da America Latina com o objetivo de ampliar $402 \mathrm{~km}$ no eixo Norte, e $220 \mathrm{~km}$ no eixo Leste, a fim de transportar água para os estados do Ceará e Paraíba ${ }^{8}$.

Ainda segundo o Ministério da Integração (2004), ações de sensibilização foram efetuadas pelo governo através dos meios de comunicação. Para o Ministério o projeto visa reduzir as disparidades sociais por meio de uma distribuição de água para as

\footnotetext{
${ }^{7}$ Projeto de Integração do Rio São Francisco com Bacias Hidrográficas no Nordeste Setentrional. Relatório de Impacto Ambiental - $\quad$ RIMA. Disponível em: <http://www.integracao.gov.br/saofrancisco/documentos/index.asp>. Publicado em julho de 2004. Acesso em: 26/09/2010.
}

8 Integração de Bacias. Eixos do Projeto. Disponível em: <http://www.integracao.gov.br/saofrancisco/integracao/eixos.asp>. Acesso em: 26/09/2010. 
populações que sofrem problemas advindos de seca; ampliar os projetos de irrigação, melhorar as vias navegáveis através da dragagem, onde é retirado areia dos rios, causando assim impactos positivos na região, pois os rios passam a possuir maior profundidade, além de proporcionar o aumento da biodiversidade. O processo de sensibilização busca a aceitação da transposição do rio São Francisco pela população brasileira, com o intuito de aumentar as chances de eficiência do projeto, que contém ações relacionadas à educação ambiental.

Destarte, nota-se que o assunto acerca do rio São Francisco perpassa a história, visto que, desde períodos longínquos o rio mostrou-se presente na vida dos brasileiros, o qual se mostra presente até mesmo como fator identitário dos moradores que viveram na região circunvizinha, pois muitos passaram períodos utilizando do rio para a sua subsistência. Além disso, a representatividade está presente até mesmo para as populações que residem nos grandes centros, visto que o rio mostrou-se presente nas bases econômicas tanto realizadas pelo comércio realizado por meio fluvial, como na criação das hidrelétricas, o que se mostra presente na realidade brasileira, ou seja, houve mudanças na utilização dos rios, mas continuam sendo importantes para a vida da população em geral.

\section{REALIDADE SERGIPANA: A UTILIZAÇÃO DOS TRANSPORTES FLUVIAIS PARA/PELO TURISMO NOS CÂNIONS DE XINGÓ E NO POVOADO DE PORTO DO MATO.}

Conforme mencionado, para a concretização desta pesquisa foi realizado um estudo exploratório, objetivando proporcionar maior familiaridade com o problema, além de torná-lo mais explícito (GIL, 2006). Além de estudo de caso, a pesquisa exploratória também se caracteriza como bibliográfica, e esta foi utilizada como base para formulação do instrumento de pesquisa. Na opinião de Gil (2006), a principal vantagem da pesquisa bibliográfica reside no fato de permitir ao investigador a garantia de uma gama de fenômenos muito mais ampla do que aquela que poderia pesquisar diretamente. 
De acordo com Cervo e Bervian (1996, p. 8): “Atualmente, a ciência é entendida como uma busca constante de soluções, de revisão e reavaliação de seus resultados [...]”. Ou seja, segundo os autores citados a pesquisa científica não é estática, sempre pode ser renovada.

Como instrumentos de pesquisa foram utilizados dados primários, onde foram realizadas duas entrevistas. A primeira foi em uma agência de viagens que comercializa o destino Xingó. O critério utilizado para a seleção da empresa foi por tratar-se de uma das mais antigas e mais atuantes a explorar os cânions. A segunda entrevista foi realizada com o presidente da Associação de Proprietários de Lanchas e Jangadas que atua em Porto do Mato. A descrição e a análise das entrevistas serão apresentadas a seguir.

\subsection{A UTILIZAÇÃO DOS TRANSPORTES FLUVIAIS TENDO COMO DESTINO O CÂNION DE XINGÓ}

Por meio de pesquisa quantitativa e qualitativa realizada em agência de viagens que comercializa o destino Xingó pôde-se observar sua atuação no mercado sergipano, a demanda existente para o destino Cânion de Xingó, e o perfil do público que busca o destino, bem como a forma de operacionalização da agência e todos os aspectos ligados à oferta em correspondência com a demanda. A pesquisa quantitativa buscou levantar a quantidade de turistas que visitam os cânions de Xingó, bem como fazer um levantamento dos meses que possuíam maiores demanda e o período sazonal da atividade turística no destino. Já a pesquisa qualitativa buscou analisar a oferta do pacote turístico realizada pela agência e os valores agregados ao produto.

Sobre o destino Cânion de Xingó foram levantados os seguintes questionamentos: Qual a média mensal de passeios realizados com destino para o cânion de Xingó; qual o valor por passageiro; qual a duração do passeio; quais os meios estavam sendo utilizados para a realização dos roteiros, desde a saída de Aracaju até o percurso final; se existia demanda sergipana em busca desse destino; qual região possuía maior demanda de turistas para o destino e quais os meses de maior demanda; o que estava incluso no valor cobrado por passageiro; durante quanto tempo à agência 
vendeu esse destino; quais os dias que ofereciam o passeio; qual o horário de saída e de retorno à Aracaju.

A agência foi selecionada porque trabalha com o destino Cânion de Xingó há duas décadas, sendo que durante 19 anos trabalhou com a venda de pacotes individuais e há um ano realizava receptivo somente para grupos de no mínimo dez pessoas.

O destino se caracterizou como o mais procurado, porém a maior demanda concentra-se nos meses de dezembro e janeiro. No período de alta estação em média foram realizados vinte passeios mensais, enquanto na baixa estação decaiu para em média dez. O passeio era ofertado de terça a domingo, somente era realizado com grupos, porém cobrava-se $\mathrm{R} \$ 110,00$ por passageiro, sendo que incluía no pacote transporte rodoviário e fluvial, e guia turístico.

A demanda sergipana apresentava-se muito baixa, os fluxos de turistas em sua grande parte vieram do Sul e Sudeste. O deslocamento desses turistas de Aracajú para Xingó era feito através de vans, micro ônibus e/ou ônibus, no entanto o passeio era realizado nas águas do São Francisco por meio de embarcações fluviais denominadas de catamarãs.

A saída era realizada às 06h30min e percorria $213 \mathrm{~km}$ até o município de Canindé de São Francisco, o passeio no cânion tinha duração de três horas sendo que, uma hora era ocupada com o banho no Velho Chico, após a realização do percurso pelo cânion os visitantes podiam almoçar no restaurante flutuante denominado de Karrancas por em média $\mathrm{R} \$ 40,00$ na alimentação para duas pessoas.

Das quartas-feiras aos domingos visitam o Museu de Arqueologia de Xingó (MAX) que retrata populações que viveram até 9000 antes na região do baixo São Francisco ou se os visitantes preferissem poderiam visitar a Companhia de Hidrelétrica do São Francisco (CHESF) onde a visita era acompanhada por um guia local e começava com a exposição de um vídeo que visava demonstrar aos visitantes o processo de construção no espaço e os impactos que uma obra de grande porte pode causar na sociedade, buscando sensibilizar os visitantes e promover a educação ambiental durante toda a visita, a última parada dá-se em uma casa de doces caseiros, onde era possível adquirir produtos da gastronomia regional, chegando a capital sergipana por volta das $19 \mathrm{~h} 30 \mathrm{~min}$. 
De acordo com a Reali (2007), em Canindé de São Francisco se encontra o quinto maior cânion navegável do mundo. Além das dimensões do cânion de Xingó ele é representativo da história de um povo, visto que retrata as vivências de indivíduos na região, que sobreviveram milhões de anos antes da sua construção e perpassa a atualidade, pois a população residente na região circunvizinha utiliza as águas do São Francisco de acordo com as necessidades sentidas.

Além disso, as águas do Velho Chico são apreciadas por turistas de diversas regiões do país e do exterior, que buscam conhecer as belezas naturais e os aspectos sócio-históricos. Entretanto, considerando que de acordo com a agência entrevistada o destino Cânion de Xingó é o mais vendido do Estado, torna-se imprescindível viabilizar um melhor planejamento que vislumbre uma melhoria de equipamentos turísticos, diversificação de entretenimento e lazer, bem como o engajamento da comunidade local no processo de desenvolvimento turístico a fim de beneficiar a todos os atores envolvidos.

\subsection{OS TRANSPORTES FLUVIAIS EM PORTO DO MATO E O ENVOLVIMENTO COMUNITÁRIO}

Esse tópico tem como objetivo explanar os aspectos geográficos da região de Porto do Mato e identificar o envolvimento da população com o meio natural e com os transportes que circundam o povoado. Devido à existência de atrativos turísticos na localidade, os quais são compostos por transportes fluviais foi realizado um estudo de caso no povoado citado e por meio de pesquisa qualitativa buscou-se esclarecer o envolvimento da comunidade com o lugar. Além disso, procurou-se através de pesquisa exploratória esclarecer a maneira que o turismo era configurado no local.

De acordo com Gomes (2010), o povoado de Porto do Mato se localiza no município de Estância, situado na região Centro-Sul do estado de Sergipe. A autora coloca que o povoado é banhado pela bacia dos rios Piauí e Real, a bacia do Piauí tem como rio principal o Piauí que nasce na Serra dos Palmares localizada em Riachão do Dantas e a do rio Real tem como rio principal o rio Real que nasce na serra do tubarão localizada no município de Poço Verde. O clima de Porto do Mato é subúmido, com 
distribuição de chuva o ano inteiro com maior concentração nos meses de abril a agosto. Faz parte da área mais úmida do Estado de Sergipe.

Também conforme coloca Gomes (2010), como forma de subsistência a população é beneficiada pelos manguezais, que proporcionam a pesca, devido à forte presença do aratu e do caranguejo, sendo que essas atividades são realizadas por meio de pequenas embarcações fluviais. Além disso, a população cultiva mandioca, mangaba e cria bovinos e galinhas.

A autora ainda usa dados do Censo 2000 (IBGE, 2001) para enfatizar que a população não é beneficiada pelo poder público em questões básicas como ensino, saúde e saneamento. De acordo com esse levantamento constatou-se que grande parte do lixo dos domicílios é enterrado o que ocasiona prejuízos nos lençóis freáticos.

Através da observação de campo em visita realizada, constatou-se de forma nítida a insipiência da infraestrutura urbana. A pesquisa também revelou que a população não acolhe da forma que deveria sequer os próprios moradores, tampouco os turistas de forma hospitaleira. A sinalização turística é inexistente, o que dificulta a chegada de turistas que não venham acompanhados por agenciadores.

Nessa mesma visita foi realizada uma entrevista semiestruturada com o então presidente da Associação de Proprietários de Lanchas e Jangadas a fim de fazer um levantamento sobre questões referentes ao desenvolvimento do turismo na localidade. $\mathrm{Na}$ entrevista o presidente da associação revelou que em Porto do Mato os rios antes somente eram utilizados para a pesca, porém após a gravação da novela Tieta em Mangue Seco no Estado da Bahia alguns moradores da comunidade se uniram e criaram uma associação denominada de ASPROLANJA (Associação de Proprietários de Lanchas e Jangadas) com o intuito de transportar as pessoas que quisessem atravessar de Porto do Mato para as ilhas denominadas de Mangue Seco, da Sogra, do Sossego, Pontal do Saco, Terra Caída, Crasto e Malvinas.

$\mathrm{Na}$ entrevista realizada com o presidente da ASPROLANJA questionou-se por que a comunidade decidiu criar a associação; qual o período de maior fluxo turístico na região pesquisada; qual a duração dos passeios oferecidos; há quanto tempo ofertavam as travessias; quais os dias que ofereciam os passeios; se existia demanda sergipana em busca do destino; qual região era maior indutora de turistas para realizar o passeio; o horário de saída das lanchas; quais os meios de transportes eram utilizados para a 
realização dos roteiros; se as pessoas que levavam os turistas para a região detinham conhecimento sobre aspectos encontrados nos destinos.

O questionamento teve o intuito de fazer um levantamento dos atrativos ofertados na região, com o objetivo de suscitar inquietação nas iniciativas públicas e privadas por meio da demonstração do potencial turístico, a fim de que haja um planejamento e conseqüentemente um desenvolvimento na região por meio do turismo.

O local é visitado por turistas nacionais e internacionais, porém a maioria vem do Sul do Brasil. Segundo o presidente da associação são poucos os sergipanos que procuram pelas embarcações para efetuar o passeio. Ainda segundo ele a Capitania dos Portos fiscaliza as embarcações semanalmente. Para que sejam aprovadas para fazer o percurso precisam ter documentação da embarcação, seguro de passageiro colete para todos os embarcados e $10 \%$ a mais, extintor e o piloto deve ser habilitado.

Mencionou que os meses de maior fluxo turístico na região eram dezembro, janeiro, fevereiro e março. Que a associação contava com três lanchas que comportavam sete pessoas, sendo que são para cinco adultos e duas crianças e vinte lanchas que abarcavam cinco passageiros. Que o passeio era realizado todos os dias das oito horas às dezessete e trinta. Ainda, que devido à falta de infraestrutura, referente à iluminação e segurança, os percursos não eram realizados a noite. A travessia era feita à noite somente em casos de atrasos na viagem.

Mangue Seco despertou o interesse das pessoas e da população em utilizar as embarcações para promover o turismo por conta, principalmente, da influencia da mídia. De acordo com o então presidente da ASPROLANJA o atracadouro da Terra Caída, o transporte fluvial até Mangue Seco tem um trajeto de apenas quinze minutos. Os passeios na baixa estação são mais baratos do que na alta e se os turistas optarem por pernoitar na localidade o aumento no preço é significativo.

Além do uso de lanchas também realizavam passeios com pequenas embarcações, denominadas de tótótó com o custo de apenas dois reais, porém a embarcação só saía quando a capacidade total de usuários fosse atingida. Em Porto do Mato existem tótótós que comportam quarenta, cinqüenta e sessenta passageiros.

O abastecimento de alimentos e bebidas para Mangue Seco também é feito a partir de Porto do Mato por meio de canoas. Segundo o presidente da ASPROLANJA 
esse transporte de $\mathrm{A} \& \mathrm{~B}$ encarece bastante o preço dos produtos que posteriormente são comercializados na ilha.

Além do presidente da associação também foram entrevistados membros da comunidade, como os marinheiros das embarcações e alguns visitantes e agentes de turismo que estavam realizando guiamento na região.

Os visitantes se encontravam no Estado devido à realização de um evento promovido pela Petrobrás que se realizava em um resort do município de Aracaju. O grupo formado por doze pessoas relataram estarem satisfeitos em conhecer os atrativos turísticos da região e desfrutarem do lazer em contato com o meio ambiente natural.

Quanto ao agente de turismo, cabe ressaltar que o mesmo transportou os doze passageiros do resort até Porto do Mato. O colaborador citado se apresentou como guia dos embarcados e marinheiro da embarcação que transportava os turistas, porém negou possuir a formação em guia de turismo. Então, para este tratado o colaborador foi considerado como agente de turismo.

O presidente da ASPROLANJA ao falar sobre o conhecimento das pessoas que operavam na região citou que, muitos colaboradores de agências de viagens desconhecem os destinos, mas levam os turistas e passam informações equivocadas. Porém, ganham em cima do valor gasto pelos turistas com os transportes fluviais, produtos de alimentos e bebidas e buggies (veículo automotor apropriado para percorrer as dunas), visto que existe uma parceria entre os denominados guias e os demais agentes de turismo.

Ainda segundo o presidente, a falta de entendimento das pessoas que acompanhavam os turistas sobre a região visitada era nítida, pois chegam ao ponto de "explicar" aos turistas que as folhas amarelas das árvores são frutos e que os caranguejos sobem nelas para se alimentarem, porém, as folhas amarelas que caem, os caranguejos puxam para o mangue e se alimentam. Dessa forma, percebeu-se que embora falte capacitação para as pessoas da comunidade, estas detêm um maior conhecimento sobre a região devido à vivência do que os guias.

O povoado tem uma grande carência em infraestrutura básica e a turística é inexistente. São poucos os horários disponíveis para o transporte rodoviário (o único modal público que trafega nessa região) para as regiões vizinhas. Além disso, não existe uma diversificação de oferta de alimentos e bebidas, próxima do local de embarque nos 
transportes fluviais. Existe apenas um local de comercialização que é o restaurante do atracadouro o qual pertence ao presidente da associação e não tem estrutura adequada para atender os visitantes.

Com relação aos programas de capacitação para a comunidade, relatou-se que recentemente foi realizado um treinamento através do Serviço Nacional de Aprendizagem Nacional (SENAC), que segundo os integrantes que participaram do treinamento aprenderam somente como recepcionar os turistas.

A pesquisa e observação de campo revelou uma possível falta de entendimento dos envolvidos com o trade sobre como era vender o turismo, pois quando os turistas indagaram o que encontrariam na ilha que iriam visitar o próprio presidente da associação respondeu que tinha "mulheres bonitas", ou seja, ao invés de ofertar bens e serviços que fazem parte do trade turístico provavelmente por falta de maior entendimento citou o ser social que nesse caso não compõe o produto turístico.

Para que o povoado esteja apto para receber turistas é preciso que haja um planejamento turístico, isso é possível através de iniciativas do governo, mesmo que estas sejam compostas da união do público com o privado. "A manutenção do meio ambiente em padrões que correspondam às necessidades dos turistas e dos habitantes das localidades turísticas [...] é responsabilidade dos governos nos níveis local, regional, nacional e internacional" (RUSCHMANN, 2002, p. 88).

O planejamento pode ser feito de forma integrada com outros locais de regiões circunvizinhas, pois assim é possível ampliar a cadeia produtiva do turismo de modo que vários destinos se beneficiem. "Deve-se estimular a criação de mecanismos de solidariedade entre localidades com recursos naturais próximos entre si e que se beneficiam, direta ou indiretamente, da atividade desse recurso" (RUSCHMANN, 2002, p. 90).

O povoado, precisa ser dotado de infraestrutura básica inicialmente, seguida de infraestrutura turística, pois o destino precisa satisfazer as necessidades dos moradores, para depois suprir as necessidades dos turistas. Assim sendo, a população local tende a aceitar ou até envolver-se com o trade turístico, e consequentemente resulta em melhorias para a comunidade.

Embora a população pesquisada nesse povoado tenha se mostrado interessada no desenvolvimento turístico, esse interesse deve ser demonstrado ou não, pela maior parte 
da mesma, pois todos têm o direito de se envolver nos processos que ocasionam danos ou melhorias para a população como um todo, e o turismo é uma dessas atividades que sem planejamento tende a trazer danos, porém com um devido planejamento os pontos positivos sobrepõem os negativos. Através desse entendimento pela comunidade e do envolvimento desta no processo a população pode exibir seus direitos de cidadão e de escolha, pois, segundo Gastal e Moesch (2007, p. 31):

O pleno exercício da cidadania supõe direitos civis, direitos políticos (participação no poder por meio do direito de associação, de livre expressão e de práticas políticas), direitos sociais (regulação do trabalho, aposentadoria, alimentação, habitação, saúde e educação) e direitos culturais.

Desse modo, nota-se que Porto do Mato possui um grande potencial turístico, porém precisa ser trabalhado junto com o poder público e a iniciativa privada, pois as pessoas da comunidade não são os únicos responsáveis e beneficiados a partir do desenvolvimento local, o problema acentua-se devido à infraestrutura básica deficiente.

\section{CONSIDERAÇÕES FINAIS}

Como ficou explicitado anteriormente o trabalho buscou trazer uma visão geral da utilização das hidrovias no Brasil, mas dar ênfase ao estado de Sergipe. Buscou-se exibir a relação entre o transporte fluvial e o turismo e mostrar que além de serem utilizados para o deslocamento, os transportes podem ser considerados parte do atrativo turístico, sobretudo, nas regiões que utilizam aquém do que o potencial existente. Também se buscou exemplificar o uso dos transportes fluviais no Estado de Sergipe, dando ênfase ao uso para/pelo turismo, a fim de demonstrar que mesmo as hidrovias brasileiras possuindo baixa densidade é possível utilizá-las e apropriá-las ao uso turístico. Entretanto conclui-se que para oferecer um produto turístico é preciso dotar a localidade de infraestrutura, bem como, capacitar os prestadores de serviços turísticos.

Nota-se que embora apenas alguns rios brasileiros não se mostrem profundos, os rios da bacia amazônica e da bacia do rio São Francisco são extensos e possuem profundidade própria para navegação, embora em alguns trechos a profundidade se 
reduza devido aos aspectos geográficos da região perpassada pelo rio ${ }^{9}$. Além disso, percebe-se a importância dos rios para a população brasileira, que desde os tempos mais remotos foram utilizados para a navegação e ainda hoje são utilizados, porém os rios vêm ganhando novos usos, como por exemplo, o turístico.

Por meio da visita em campo e da pesquisa aplicada na agência, notou-se que o cânion de Xingó atrai turistas, sobretudo nacionais a fim de conhecer os aspectos que constituem a região do baixo São Francisco. Porém, percebeu-se que é necessário haver um planejamento turístico de forma integrada, pois para consolidar a atividade turística é necessário envolver os atores sociais nos processos de desenvolvimento turístico. A pesquisa revelou que a renda deixada no município concentra-se no Restaurante Karrancas e o gasto com as embarcações, sendo que a maior parte da população não é beneficiada pelo turismo. $\mathrm{O}$ estudo também demonstrou que por a duração do passeio ser de apenas um dia os turistas não exploram em sua totalidade os atrativos naturais e culturais existentes na região.

A pesquisa qualitativa realizada com a comunidade local e com turistas proporcionou fazer um levantamento dos passeios oferecidos no povoado e conhecer os transportes fluviais utilizados pelos moradores antes e depois de criarem a associação, bem como de perceber que a comunidade local detém conhecimentos a partir das vivências, mas necessitam de capacitação, pois somente veio contar com essa aprendizagem atualmente, efetuada pelo SENAC, que é inteiramente voltada para o atendimento ao turista, ou seja, é preciso ampliar bastante os treinamentos para capacitar os indivíduos, que se mostraram interessados pelo setor turístico.

Portanto, é recomendável a criação de um planejamento no município pelo poder público, juntamente com a iniciativa privada, com a participação da sociedade civil organizada, que direcione ações e projetos a fim de capacitar os moradores de Porto do Mato, para que haja um desenvolvimento local sustentável a partir do turismo. O povoado estudado mostra-se bastante instigador, pois os moradores estão dispostos a receber os turistas e deram os primeiros passos, criando uma associação a fim de que haja desenvolvimento local através do turismo, entretanto não receberam o apoio necessário para consolidar a atividade turística na região.

\footnotetext{
9 Navegação Fluvial. Marinha do Brasil. Disponível em: <https://www.mar.mil.br/dhn/bhmn/download/cap-40.pdf>. Acesso em: 29/08/2011.
} 
O estudo concluiu que há uma discrepância entre os atrativos pesquisados. Enquanto os cânions de Xingó conseguem explorar razoavelmente o seu potencial enquanto atrativo turístico, o povoado de Porto do Mato aparenta ser subutilizado. Pode-se notar que se trata de um local rico em recursos que podem ser trabalhados no turismo, pois é constituído de manguezal, além de ser banhado por rios o que proporciona o uso de transportes fluviais, entretanto, não existe infraestrutura adequada para o recebimento de turistas.

Deste modo é indispensável que haja parceria do público com o privado a fim de ofertar melhores produtos turísticos e desconcentrar a renda gerada pelo turismo. A população deve estar inserida no processo e ser beneficiada através do turismo, então é de fundamental importância buscar prolongar os dias de visita dos turistas a fim de que conheçam melhor os aspectos histórico-culturais e ao mesmo tempo usufruam os serviços ofertados em ambos os destinos estudados.

\section{REFERÊNCIAS}

CENSO DEMOGRÁFICO 2000: características da população e dos domicílios: resultados do universo. Rio de Janeiro: IBGE, 2001. Acompanha CD-ROM

CERVO, A. L; BERVIAN, P. A. Metodologia científica. 4. ed. São Paulo: Makroon Books, 1996. p. 5-19.

DI RONÁ, R. Transportes no turismo. São Paulo: Manole, 2002.

FREYRE, G. Nordeste: aspectos da influência da cana sobre a vida e a paisagem do Nordeste no Brasil. 7. ed. São Paulo: Global, 2004.

GASTAL, S.; MOESCH, M. M. Turismo, políticas públicas e cidadania. São Paulo: Aleph, 2007.

GIL, A. C. Como elaborar projetos de pesquisa. 4. ed. 8. reimpr. São Paulo: Atlas, 2006.

GOMES, L. 1808 - Como uma rainha louca, um príncipe medroso e uma corte corrupta enganaram Napoleão e mudaram a História de Portugal e do Brasil. $2^{\mathrm{a}}$ reimpressão. São Paulo: Planeta do Brasil, 2007. 
GOMES, R. C. S. Caracterização geoambiental do povoado Porto do Mato Estância/SE: uma análise do lugar. São Cristóvão: UFS, 2007. Disponível em: <http://www.scientiaplena.org.br/sp_v3n5p107_116.pdf>. Acesso em: 22/09/2010.

GOULARTI FILHO, A. Padrão de crescimento e sistema de transportes em Santa Catarina, 1880-1945. Am. Lat. Hist. Econ, México, n. 34, dic. 2010. Disponível em: <http://www.scielo.org.mx/scielo.php?script=sci_arttext\&pid=S1405-

22532010000200005\&lang=pt>. Publicado em julho de 2010. Acesso em: 07/ 05/ 2011.

MARQUES, T. M. F. As hidrovias na ocupação do território - Contribuições. In: CASTROGIOVANNI, A. C. (org.). Inquietações Geográficas. Porto Alegre: Dos autores, 2000.

MINISTÉRIO DA INTEGRAÇÃO NACIONAL. Integração de Bacias. Disponível em: 〈http://www.integracao.gov.br/saofrancisco/integracao/eixos.asp>. Acesso em: 26/09/2010a.

- O Rio e seus números. Disponível em: <http://www.integracao.gov.br/saofrancisco/rio/index.asp>. Acesso em: 14/09/2010b.

Projeto de integração do rio São Francisco com bacias hidrográficas no Nordeste Setentrional. Relatório de Impacto Ambiental - RIMA. Disponível em: <http://www.integracao.gov.br/saofrancisco/documentos/index.asp>. Publicado em julho de 2004. Acessado em: 26/09/2010.

OLIVA. J. A. B. Cenário atual do transporte hidroviário brasileiro. In: SEMINÁRIO INTERNACIONAL EM LOGÍSTICA AGROINDUSTRIAL, 5. "O Transporte Hidroviário (Fluvial e Cabotagem) de Granéis Agrícolas". Brasília: ANTAQ, 2008. (Apresentação Power Point). Disponível em: <http://www.antaq.gov.br/portal/pdf/palestras/Mar0817PiracicabaAlexOliva.pdf>.

Acesso em: 02/09/2011.

OLIVA, T. J. Guie a turma pela Amazônia. Revista Nova Escola, São Paulo, Ano XVII, n. 151, abril de 2002. Disponível em: <http://revistaescola.abril.com.br/ensinomedio/guie-turma-pela-amazonia-425636.shtml>. Acesso em: 14/09/2010.

REALI, H. e S. Canindé de São Francisco Turismo na Caatinga. Revista Planeta. Editora Três: São Paulo, 2007.

RUSCHMANN, D. V. de M. Turismo e planejamento sustentável: a proteção do meio ambiente. 9. ed. Campinas, São Paulo: Papirus, 2002.

Recebido em: 03-07-2011.

Aprovado em: 03-08-2011. 